\title{
Ningaloo from a systems perspective - what has it taught us?
}

\author{
$\underline{\text { Elizabeth A. Fulton }}^{a}$, Randall Gray ${ }^{a}$, Miriana Sporcic ${ }^{a}$, Roger Scott $^{\mathrm{a}}$, Bec Gorton ${ }^{\mathrm{a}}$, Mark Hepburn ${ }^{\mathrm{a}}$, \\ Fabio Boschettia and Linda Thomas ${ }^{\mathrm{a}}$ \\ ${ }^{a}$ Wealth from Oceans Flagship, CSIRO, Marine and Atmospheric Division, GPO Box 1538, Hobart, Tas, \\ Australia. Phone: 61-3-62325018 \\ Email: beth.fulton@,csiro.au
}

\begin{abstract}
A system-level perspective of exploited marine and coastal ecosystems provides insight into cross-scale dynamics and potential conflicts between sectors operating within the same region. Such insights are a necessary part of adaptive management, as conflict and 'surprise' outcomes of interactions between processes operating on different scales could undermine the intent of management actions taken in support of sustainable development. Agent-based models provide one means of obtaining the desired system perspective. These types of models are one of the few platforms that can deal with the large number of scales and processes that can drive the alternative states that socioecological systems can take. By defining individual-based approaches and both differential and discrete equation-based formulations as agents sufficient flexibility is provided to create cross-scale whole-of-system models that can include biophysical, social and economic drivers and interactions. This combination of agent types and the resulting flexibility has provided essential for identifying trade-offs between sectors, identifying "unintended consequences" and supporting the implementation of adaptive management in the Ningaloo Reef - Exmouth system of Western Australia.
\end{abstract}

Keywords: multiple use management, multi-scale models, agent based models 
Fulton et al., Ningaloo from a systems perspective - what has it taught us?

\section{INTRODUCTION}

The ultimate aim of environmental management research is to provide a science-based foundation for decision makers, state and local government employers and others involved in the use and management of natural resources. Moreover, the aim is to provide the information in such a way that it provides knowledge both for policy making and day-to-day operations. When dealing with coastal and near shore marine environments this means drawing together information on many different biophysical, social and economic aspects of the overall system. This in turn means handling a broad range of scales from sub-metre to hundreds of kilometres. The modelling applied to the Ningaloo-Exmouth region is a good example of how a system-level model can help provide insights into the potential benefits, weaknesses, conflicts and tradeoffs associated with alternative development futures and management strategies.

The first modelling step was to draw together data from historical sources as well as the recent WAMSI and Ningaloo collaboration cluster projects carried out in the region. This synthesis provided information on the current system state, its functioning and likely responses to future pressures. This knowledge was then used to generate projections of possible future regional development. The approach used to create these projections was the Management Strategy Evaluation (MSE) framework. This framework simulates the different steps in adaptive management; specifically resource dynamics, actions of those exploiting the resource, any management strategies and associated monitoring systems proposed or in place. By spanning such a complete representation of the management process potential responses under management strategies can be tracked, which allows for an assessment of the performance of the strategies as well as the identification of tradeoffs between management objectives, all within the context of a range of uncertainties about resource and industry dynamics (Butterworth et al. 1998; Cochrane et al. 1998; Butterworth and Punt 1999; Sainsbury et al. 2000). The MSE approach intentionally moves away from the idea of equilibrium and optimal outcomes and when applied to entire ecosystems. It embraces the dynamic nature of these socialecological systems, and views management as adaptation to shifts in systems (regardless of whether the cause is environmental, ecological, economical or social ). This makes the approach particularly well suited to complex and intermingled systems like the Ningaloo-Exmouth region.

In the Ningaloo-Exmouth implementation of MSE 'model building' was seen as a strong catalyst for discussion (which is typical for MSE), but also for expanding the direct experience of the different interest groups with the nonlinear dynamics of complex systems. This meant that a single comprehensive model was not the sole aim of the process. Instead, a range of models was used to form conceptual understanding of system function, instruct on complex systems and explore the system (many of these models are reported elsewhere in this volume, so only the InVitro model will be reported here). The extensive interactions with interested groups in the region and Perth, in support of the use of these models, represented a requirement for gaining information on the system critical to model development, but also provided on-going opportunities to ensure that the final compliment of models remained relevant to businesses, managers and communities (which is critical if they are to have ongoing use). Consequently, 'model building ' became an adaptive process, influenced by stakeholders.

Considerable effort was put into engagement as the most common ways that science can fail to inform management (Elzinga et al. 1998, Lee 1999) are:

1. data access is poor (either because the data has not been collected or because it is held in confidence);

2. lack of engagement with managers (and other resource users) leads to a failure to ask useful questions and no clear pathway of delivering information to decision makers; and

3. information presented in classical scientific formats can be impenetrable to managers (and other resource users) meaning they fail to incorporate it into their decision making process.

The latter is the most common and most disappointing - especially given the effort and funds put into monitoring. While inconclusive results (that do not give clear indications for managers either way) can't be guaranteed against, and managers will always have to act in the context of external political and social considerations, effort must be put into effective communication of results.

\section{THE NINGALOO-EXMOUTH REGION}

Ningaloo Reef and Exmouth Gulf lies within the Gascoyne region of Western Australia (Figure 1). The area is sparsely populated, with its town largely a result of the pattern of development of the pastoralism industry, which still makes up $80 \%$ of the land tenure, in the late 1800 s (when wool from the region was shipped to 
national and international markets). Today the economy has diversified to include tourism and many other sectors. The region is the focus of high tourism visitation due to its exceptional beauty (based around a $300 \mathrm{~km}$ fringing coral reef and on-land attractions, such as those in Cape Range). Increasing industrial development in the broader northwestern area of Australia, largely based around oil and gas extraction and mining, is also providing new challenges for the region. This close geographic association of the Ningaloo Reef (currently under consideration for classification as a WHA), other reserves (e.g. Cape Range National Park), tourism and the diversity of local activities (e.g. farming, fishing and oil and gas exploration) mean that any future development must be done carefully if sustainability is to be maintained and unintended consequences avoided.

\section{THE MODEL}

One of the greatest hurdles for modelling the Ningaloo-Exmouth region is that it is a system defined by the importance of extremes of scale - from the finest of reef scale interactions up to regional current, climate and human use patterns, through to and global influences (e.g. on fuel prices, industrial demand and the tourism market). A further complicating factor is that management jurisdictions do not always match other breakpoints within the system. For instance, ecologically species assemblages show a clear break west and east of the northern tip of North West Cape. There is some degree of spatial segregation of activities (with reef associated industries to one side, extractive activities in the Gulf on the other, with agriculture and other land-based activities in between), but this segregation is not iron caste and with increasing oil and gas development within $20-50 \mathrm{~km}$ of the Ningaloo Reef Marine Park boundaries the historical patterns are blurring. Moreover, while some aspects of the ecological break is reflected in the placement of marine reserves, many other sectors do not distinguish between the areas and the resident human population considers the region as an integrated whole.

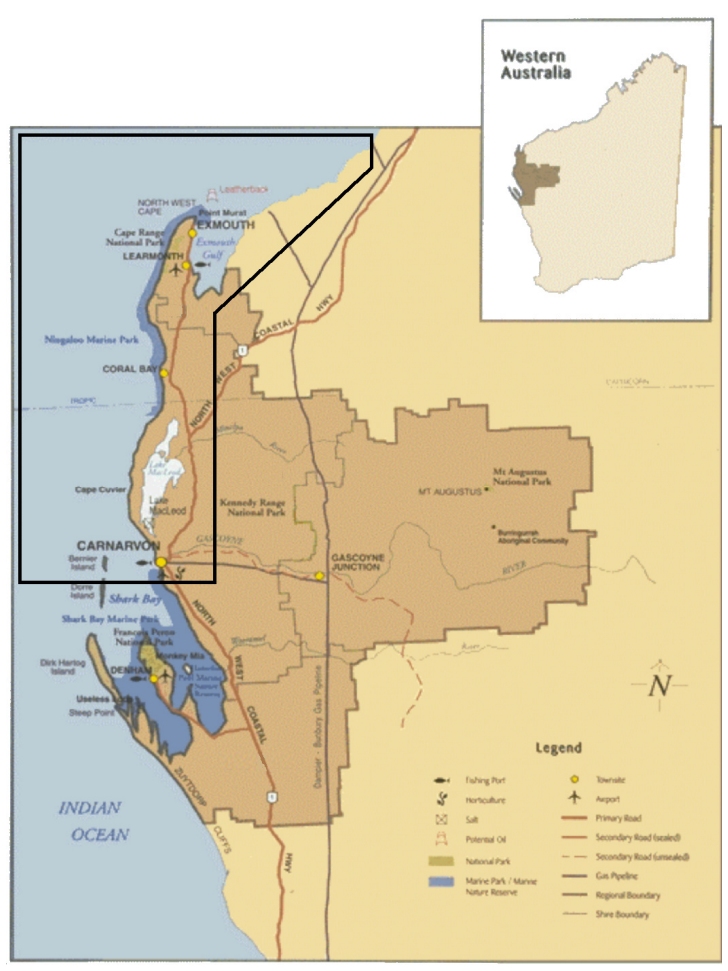

Figure 1. Gascoyne region of Western Australia. The model domain is indicated by a black box.

\subsection{InVitro}

The model used in this study was InVitro (Gray et al. 2006), a whole-of-system agent-based model, which consists of five main sub-models: 1) biophysics, which defines the natural environment, 2) socio-economics, which defines human behaviour, 3) industry, which defines large-scale economic drivers and institutions, 4) management, involving decision making and 5) monitoring and assessment (Figure 2). This modular design not only provides flexibility, via providing a choice of alternative representations for each sub-model, but also simulates biophysical, ecological and anthropogenic processes using a mix of analytical equation-based formulations (particularly for system-scale, physics or lower trophic level processes) and algorithmic, individual-based behavioural models (for rare species, top-level predators or human activities occurring at the finest scales). Each sub-model runs at the appropriate time and spatial scale.

The Ningaloo-Exmouth implementation of InVitro (Figure 3) has an oceanographic and climate sub-model (including rainfall, temperature, salinity, geomorphology, nutrient and contaminant layers); 60 ecological components (e.g. primary producers, benthic habitats, benthic invertebrate communities, pelagic forage fish, main target species of fin-fish and crustaceans, top predators and species of special interest like turtles) that make up the food-web and habitats; and representations of each of the main industries (including commercial and recreational fisheries, tourism, oil and gas, salt production, coastal development, pastoral leases, horticulture, ports, shipping and road transport, regional economics, catchment use, recreation, conservation and infrastructure like roads and pipelines). These industry models are a combination of analytical decision models, response functions, specified rules, historical data and scenarios. Uncertainty is included in each of 
Fulton et al., Ningaloo from a systems perspective - what has it taught us?

these options and determines which activity is carried out and its outcome. This aims to capture natural ambiguity in human and animal behaviour, missing or incorrect information and unpredictable and catastrophic events.

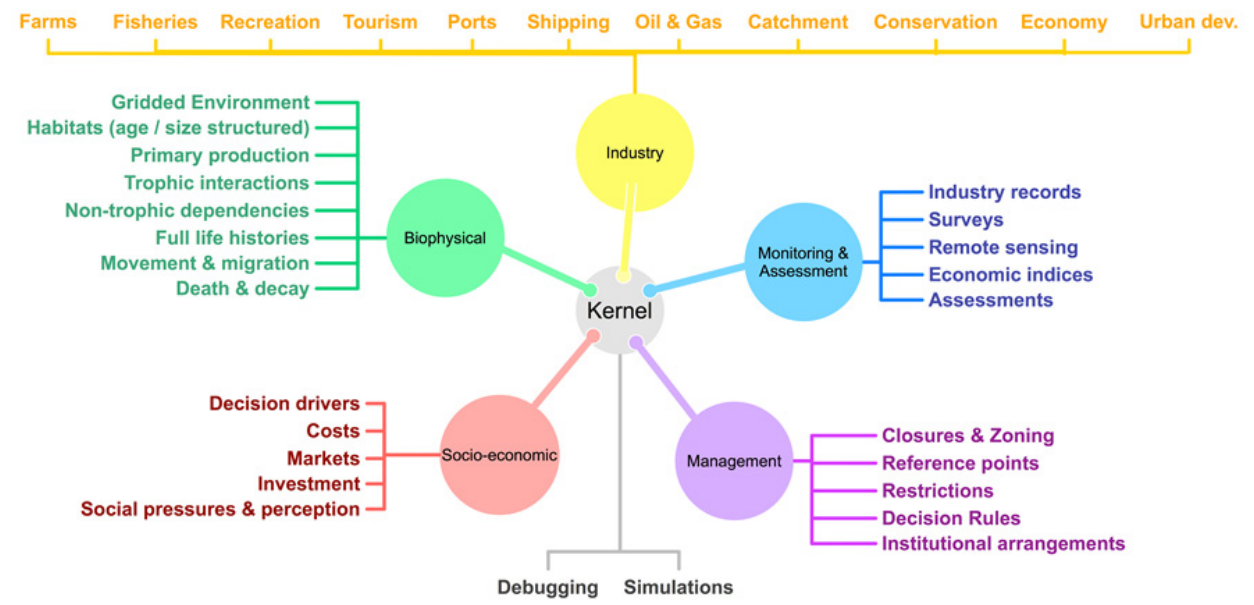

Figure 2. Main components of the InVitro modelling framework.

The Ningaloo-Exmouth InVitro model was based on data from a broad range of sources, primarily data directly collected by members of the Ningaloo research program (which ran 2005-2010), data from government departments (federal and state, including the Western Australian Department of Fisheries, Department of Environment and Conservation, Department of Transport, Department of Planning, Department of Lands), annual reports by industry members, and from the shires of Carnarvon and Exmouth. Where any gaps remained, data was drawn from neighbouring systems (e.g. the Pilbara) or environments with similar properties or structures (e.g. Great Barrier Reef).

\section{SCENARIOS}

A wide range of management strategies and contextual scenarios were defined during extensive interaction with groups interested in the Ningaloo-Exmouth region. Key questions revolved around the effects of a range of developments (from the existing Ningaloo Regional Strategy, to hypothetical developments based on new camp sites, a large resort, the paving of the Gnaraloo road and resident developments driven by the growth of the oil and gas industry in the region) and management strategies (including extended spatial management, alternative fishing regulations and increased education and enforcement).

\section{RESULTS}

The results of the model simulations highlighted the complex relationships between development and environmental status in the region. The fish stocks have already been depleted due to increasing fishing pressure (especially recreational pressure) over the last 20 years. The simulations clearly show that any further growth in this pressure leads to significant declines in biomass vs the 2007 state (which in itself was modified from an untouched state). Additional recreational pressure applied by oil and gas workers may be sufficient to cause a collapse in some key stocks that anglers prefer (Figure 3). 


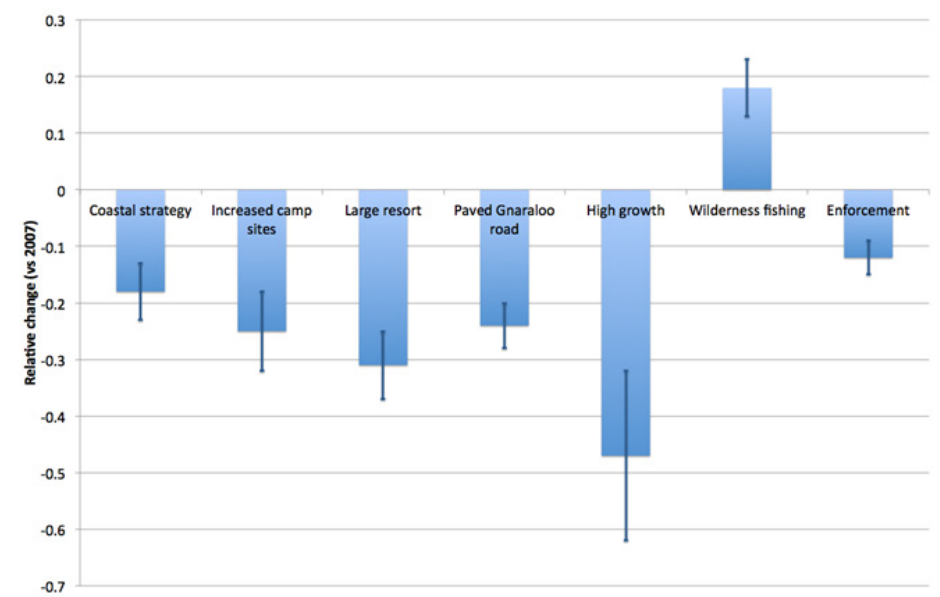

Figure 3. Relative change in biomass under alternative future development scenarios or management strategies
The simulations also indicate that without development of some form (whether tourism or other industries) there is a significant risk of the population decline (Figure 4a) of previous decades being renewed as the population ages, the younger generations move away and the working age population turns over frequently (Figure 4b). The highest proportional contribution of working age residents is when industrial growth is high, as the area is attracts new workers. Given the interaction of

population size and fishing pressure this suggests that there is a direct conflict between economic and conservation objectives. However, sustainable futures are possible, but they likely require significant changes to existing regulations (e.g. adopting ideas like "wilderness fishing" where only 1-2 fish can be taken per day for consumption that evening, though enforcement of such a concept may be difficult in reality). Even with significant management changes some components of the system may be very difficult to protect against the

(a)

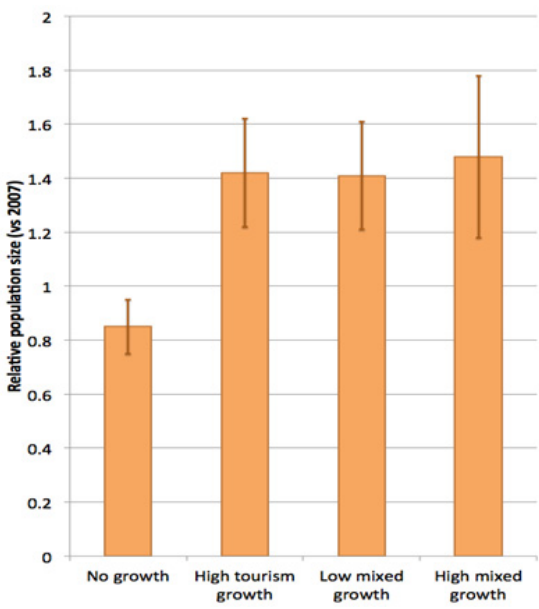

(b)

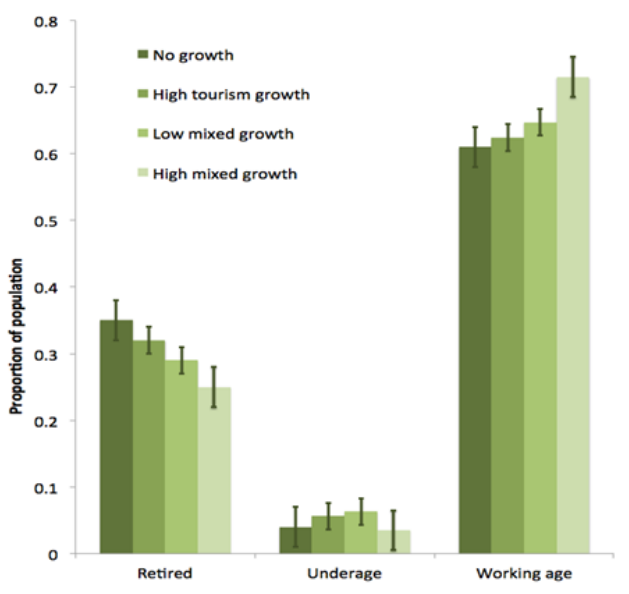

Figure 4. Relative changes and make up of Exmouth town population in 2037 under the alternative future development patterns: (a) relative population size (vs 2007), (b) proportional population make-up for Exmouth 2037

effects of anthropogenically induced climate change and ocean acidification (e.g. turtle beaches may be swamped by synergistic effects of rising sea levels of changing storm frequencies or intensities).

\section{DISCUSSION AND CONCLUSIONS}

Very diverse futures are possible for the Ningaloo-Exmouth region over the next 30 years. Fortunately, it appears management interventions are available to steer (at least some components) towards desired directions. Among these management strategies, fishing regulations, housing plans, marketing and catering for specific tourists type and infrastructure development are likely to provide the largest impact. While some 
of these results were evident in other smaller models of the system (see other papers in this volume) the interconnection between the industrial developments and larger marine state (even though not physically colocated) was only evident once the system information was integrated in the model. This information should help guide decision makers and the local community as they wrestle with their specific concerns around fishing and conservation zoning, returning the coastal strip from pastoral leases to State Government management, potential World Heritage Area listing, alternative regimes of land release for development and the likely impact of construction of new landing areas, bitumen roads and other infrastructure.

Despite the system dynamic understanding gained from this study, perhaps the even bigger lessons have been around how to (i) successfully communicate complex information to people with varying degrees of scientific background, and (ii) support these communities to let them understand and deal with complex highly interconnected systems. While the InVitro model described here can provide valuable information, its usefulness depends on whether the results and recommendations are taken up by stakeholders, which in turn depends on engaging them and addressing their concerns. By the end of the project this engagement accounted for roughly $43 \%$ of the overall modelling team's effort and resulted in a number of one-to-one meetings, workshops and seminars. This level of engagement highlighted that: a) stakeholders have very different levels of knowledge and understanding of modelling, what it does and what it can provide, which affects their attitude towards its use in planning and decision making; b) allowing stakeholders to play with simpler models that still capture key nonlinearities of the system (e.g. the other models described in this volume) can provide experience in dealing with complex systems (e.g. significant insights were gained by shore council members during training workshops held in Exmouth); c) the network of interactions among stakeholders and/or researchers can change as a result of one-to-one meetings, workshops and model use; d) the style, language and attitude required to showcase models and results differ considerably depending on the stakeholder types and expectations; e) communities hold local knowledge that can greatly benefit model development and tuning; f) similarly, communities and stakeholders may formulate questions not envisaged by modellers and project developers; and g) the level of community reception depends crucially on the amount of effort locally invested - this is true especially when scientists need to overcome the perception of being 'outsiders' to both the community and problem. These lessons around successful engagement are perhaps the most important environmental research lessons gained from a system level understanding of Ningaloo - including the role of science. To successfully provide for science-based management outcomes relevant information must be effectively communicated.

\section{ACKNOWLEDGMENTS}

We would like to acknowledge the assistance and data provided by researchers participating in the WAMSI and Collaboration cluster funded Ningaloo research, the Western Australian Department of Environment and Conservation, Western Australian Department of, and the Department of Planning and Transport. Also a very special thank goes to the local residents and the tourism operators, industry representatives, council members, hotel and hospitality owners, pastoral station owners who provided time, information, helpful suggestions and most of all their good will as well as to all the people who took time out of their busy schedules to meet with us and attend our workshops.

\section{REFERENCES}

Butterworth, D.S., and Punt, A.E. (1999) Experiences in the evaluation and implementation of management procedures. ICES Journal of Marine Science, 56: 985-998.

Butterworth, D. S., Cowan, C. L., and Johnston, S. J. (1998) The development of a management procedure for Namibian seals. Report to the Ministry of Fisheries and Marine Resources, Namibia. 47 pp.

Cochrane, K. L., Butterworth, D. S., De Oliveria, J. A. A., and Roel, B. A. (1998) Management procedures in a fishery based on highly variable stocks and with conflicting objectives: experiences in the South African pelagic fishery. Reviews in Fish Biology and Fisheries, 8: 177-214.

Elzinga, C.L., Salzer, D. W. and Willoughby, J. W. (1998) Measuring and Monitoring Plant Populations. Denver, CO: Bureau of Land Management. BLM Technical Reference 1730-1

Gray, R., Fulton, E.A., Little, L.R. and Scott, R. (2006) Operating model specification within an agent based framework. North West Shelf Joint Environmental Management Study Technical Report, Vol 16. CSIRO

Lee, K.N. (1999) Appraising adaptive management. Conservation Ecology, 3(2): 3

Sainsbury, K.J., Punt, A.E. and Smith, A.D.M. (2000) Design of operational management strategies for achieving fishery ecosystem objectives. ICES Journal of Marine Science, 57: 731-741. 